Review

\title{
Antibody Glycosylation and Inflammation
}

\section{Kai-Ting C. Shade and Robert M. Anthony *}

Center for Immunology and Inflammatory Diseases, Division of Rheumatology, Allergy, and Immunology, Massachusetts General Hospital, Harvard Medical School, Charlestown, MA 02129, USA

* Author to whom correspondence should be addressed; E-Mail: robert.anthony@mgh.harvard.edu.

Received: 3 April 2013; in revised form: 11 June 2013 / Accepted: 18 June 2013 /

Published: 25 June 2013

\begin{abstract}
IgG antibodies are the basis of some of the most effective therapeutics developed over the last 20 years. These antibodies are highly specific, have long serum-half lives, and can be produced relatively routinely, making them ideal drugs for immunotherapy. The degree of regulation on IgG antibody effector functions by the composition of the single, $\mathrm{N}$-linked glycan attached to the $\mathrm{Fc}$ is increasingly appreciated. IgG antibodies with identical protein sequences can gain a 50-fold potency, in terms of initiating antibody-dependent cellular cytotoxicity (ADCC) by removal of the single fucose residue from the Fc glycan. Conversely, the addition of sialic acid to the terminus of the Fc glycan converts IgG antibodies into anti-inflammatory mediators, capable of suppressing autoantibody driven inflammation. This review will discuss the contribution of the Fc glycan to IgG antibody effector functions, the regulation of the antibody glycosylation in vivo, implications for the rational design of $\operatorname{IgG}$ antibody-based therapeutics, and touch upon the contribution of glycosylation to other immunoglobulin isotypes.
\end{abstract}

Keywords: immunoglobulin; ADCC; anti-inflammatory

\section{Introduction}

Antibodies play key roles in humoral adaptive immune response by binding to specific antigens and linking them to the innate immune system. The ability of antibodies to harness such immunity is attributed to their unique structure, and has been successfully exploited in development of therapeutic treatments for many disease types, including cancers, autoimmune diseases, and inflammatory disorders [1-7]. 
Antibodies are comprised of basic structural units of two identical heavy and two identical light polypeptide chains. These chains are linked by disulfide bonds forming a "Y"-shaped structure [8]. Human immunoglobulins can be categorized into five classes (IgG, IgA, IgD, IgE, and IgM) referencing the heavy chain. IgG and IgA antibodies are further separated into four (IgG1-4) and two subclasses (IgA1-2), respectively. Recognition of specific antigens is mediated by the antigen-binding fragment (Fab), corresponding to the top ends of the fork of the Y-shaped structure (Figure 1). Effector functions are initiated by binding of the fragment crystallizable region $(\mathrm{Fc})$, the stem of the $\mathrm{Y}$, to effector proteins such as Fc receptors (FcRs). The Fab fragments are comprised of variable and constant domains of light and heavy chains, while Fc fragments are comprised entirely of constant domains of heavy chains. Each antibody class has distinct circulation profiles and effector functions. In serum, the most abundant class with longest half-life is IgG comprising $75 \%$ of antibodies in circulation. IgM and IgA are the next most abundant at $10 \%$ and $15 \%$, respectively and have markedly shorter serum half-lives. On the other hand, in mucosal secretion, IgA is the most abundant class and acts as the first line of defense against pathogens invading at the mucosal sites [9]. IgE is the least abundant in the circulation $(<0.01 \%)$, however, it can remain in tissues bound to receptors on mast cells for up to two weeks [10].

Immunoglobulins elicit their effector functions through interactions of the Fc portion with distinct target molecules and receptors. A single N-linked glycan is present in the Fc portion of all $\operatorname{IgG}$ subclasses. This glycan is essential for initiation of many IgG effector functions. Additionally, each antibody class has unique glycosylation profile which will be discussed in more details in the following sections. This review will focus on the contribution of the glycan to $\operatorname{IgG}$ biology, and will discuss $\operatorname{IgE}$, IgA, and IgM glycobiology.

\section{IgG and FcyRs}

IgG mediates an array of effector functions by its ability to interact specifically with Fc $\gamma$ receptors (Fc $\gamma R s$ ), the neonatal FcR (FcRn), and the initiator of the classical complement cascade, C1q. Members in the canonical Fc $\gamma R$ family can be classified into activating and inhibitory Fc $\gamma$ Rs. Initiation of the activating or inhibitory signal cascade requires Fc $\gamma \mathrm{R}$ aggregation as a result of Fc $\gamma \mathrm{R}$ cross-linking by

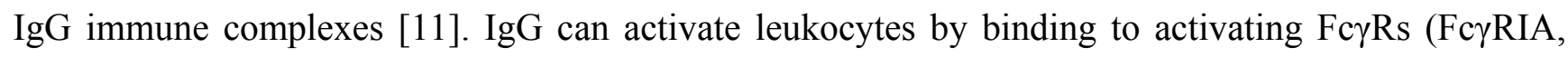
Fc $\gamma$ RIIA, Fc $\gamma$ RIIC, and Fc $\gamma$ RIIIA) that typically signal through an immunoreceptor tyrosine-based activation motif (ITAM). Activation of this signaling pathway leads to pro-inflammatory activity resulting in destruction and clearance of antigens by phagocytosis, ADCC, and promotion of antigen presentation [12]. In contrast, IgG binding to the inhibitory Fc $\gamma$ R (Fc $\gamma$ RIIB) triggers signals through an immunoreceptor tyrosine-based inhibitory motif (ITIM), thereby dampening cellular activation. Many immune cells including macrophages, dendritic cells, neutrophils express both activating and inhibitory Fc $\gamma$ Rs, the eventual signal elicited by IgG is governed by the affinity of IgG subclasses to distinct Fc $\gamma$ Rs $\left(\mathrm{K}_{\mathrm{d}}=10^{-7}-10^{-9} \mathrm{M}\right)$ and the combination of expression level and pattern of Fc $\gamma$ Rs [13-15]. 
Figure 1. Schematic representation of the human IgG structure and glycan composition. (A) IgG structure. IgG protein is comprised of two heavy chains (black outline) and two light chains (blue outline). Each IgG heavy chain has the variable region $\left(\mathrm{V}_{\mathrm{H}}\right)$ and the constant region containing three domains $(\mathrm{C} \gamma 1-3)$. The line between $\mathrm{C} \gamma 1$ and $\mathrm{C} \gamma 2$ represents the hinge region. Each light chain has variable $\left(\mathrm{V}_{\mathrm{L}}\right)$ and constant regions $\left(\mathrm{C}_{\mathrm{L}}\right)$. IgG molecule can be divided into antigen-binding fragment (Fab; empty ovals) and fragment crystallizable region (Fc; pink ovals). The red dot represents N-linked glycans of complex-type. (B) Composition of complex-type N-linked glycan on IgG. The glycan has a biantennary heptasaccharide core (solid line and in the gray block) and variable extensions (dash line). Abbreviations: F, fucose; N, GlcNAc; M, mannose; G, galactose; S, sialic acid. The enzymes, glycosyltransferases (left arrow) and glycosidases (right arrow), responsible for the addition or removal of the specific sugar are placed directly underneath of the sugar linkage. (C) Design of glycan composition on IgG Fc for potential antibody therapeutics.

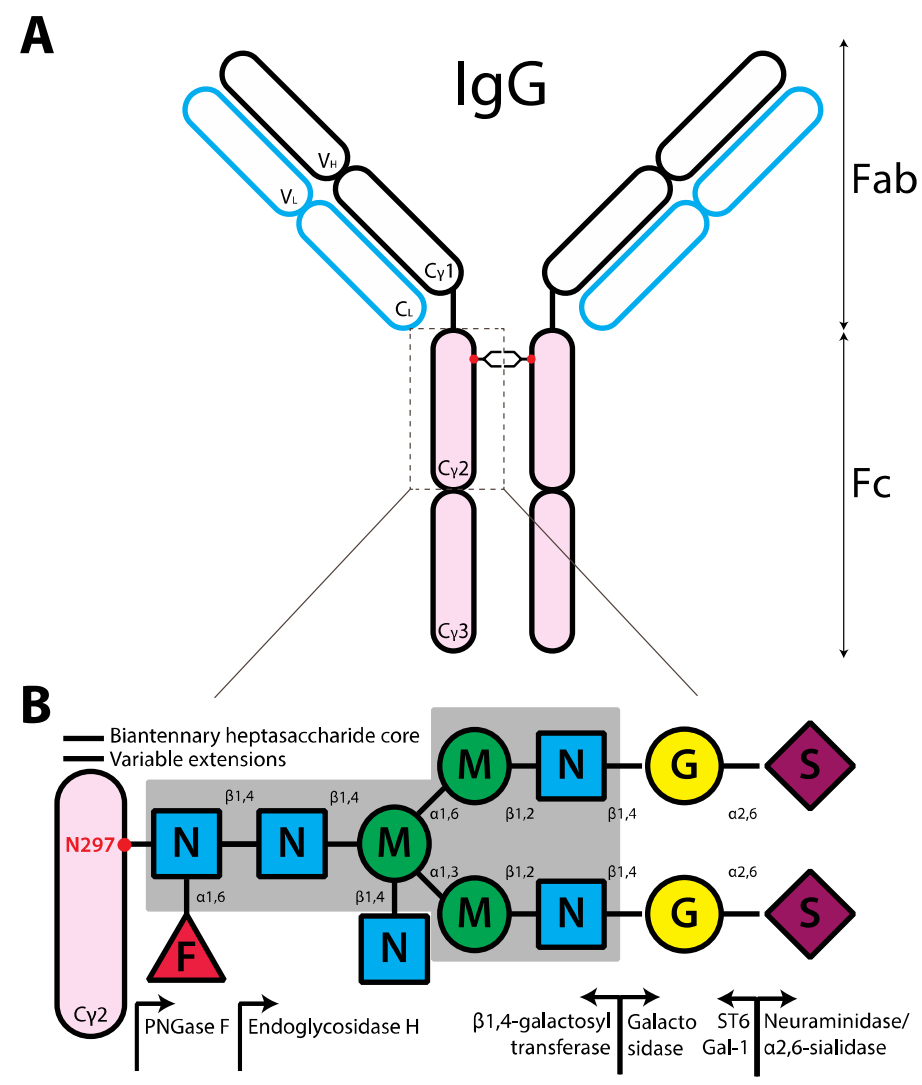

Complex-type N-linked glycan

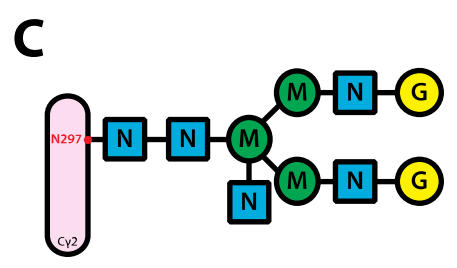

Pro-inflammatory for immunotherapy

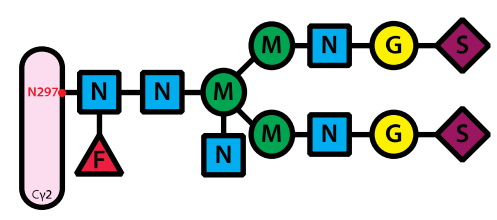

Anti-inflammatory for autoimmune diseases 
To predict the degree of pro-inflammatory activity of a specific isotype, the binding affinity of a particular $\mathrm{IgG}$ isotype for an activating Fc $\gamma \mathrm{R}$ in relation to the inhibitory Fc $\gamma \mathrm{RIIB}$, activating-to-inhibitory (A/I) ratio, can be applied [16]. For example, a ratio of 1 indicates no preferential binding to either activating or inhibitory Fc $\gamma$ Rs and a ratio above or below 1 indicates a preferred binding to the activating or inhibitory $\mathrm{Fc} \gamma \mathrm{R}$, respectively. Thus, increasing A/I ratios are indicative of more potent ADCC induction [16]. In human, IgG3 has the largest A/I ratio followed by IgG1 subclasses, indicating that IgG3 or IgG1 would be good candidates for therapeutic antibodies to elicit ADCC. Furthermore, polymorphisms of human Fc $\gamma$ RIIA and Fc $\gamma$ RIIIA allotypes are known to alter the binding affinity to IgG. Studies have shown that Fc $\gamma$ RIIIA $158^{\mathrm{V} / \mathrm{V}}$ and Fc $\gamma$ RIIA $131^{\mathrm{H} / \mathrm{H}}$ peripheral blood mononuclear cells (PBMC) exhibit a higher affinity to IgG and also an enhanced ADCC compared to their respective Fc $\gamma$ RIIIA $158^{\mathrm{F} / \mathrm{F}}$ and Fc $\gamma$ RIIA $131^{\mathrm{R} / \mathrm{R}}$ allotypes [17-22]. Indeed, an improved clinical response has also been associated with Fc $\gamma$ RIIIA $158^{\mathrm{V} / \mathrm{V}}$ or FcyRIIA $131^{\mathrm{H} / \mathrm{H}}$ patients treated with therapeutic monoclonal antibody IgG1, including anti-CD20 (Rituximab) for follicular lymphoma [23], anti-Human Epidermal Growth Factor Receptor 2 (HER2) (Trastuzumab) for metastatic breast cancer [22,24], and anti-epidermal growth factor receptor (EGFR) (Cetuximab) for metastatic colorectal cancer [25]. Furthermore, a study demonstrated that modification of the amino acid residues at the binding pocket of Trastuzumab to Fc $\gamma$ Rs increased the affinity and also ADCC to the lower-affinity allotype Fc $\gamma$ RIIIA $158^{\mathrm{F} / \mathrm{F}}$ [18]. Thus, maximizing the A/I ratio by pairing an optimized variant of a particular antibody isotype to the patient allotypes is likely to improve the clinical efficacy mediated by therapeutic antibodies.

In addition to the canonical FcyRs, IgG binds to a major histocompatibility complex (MHC) class I-related receptor, neonatal FcR (FcRn). This interaction elicits two main functions: it allows transcellular transportation of maternal IgG to foetus across the placenta, and it prolongs the half-life of serum IgG by preventing degradation from catabolism [26]. Thus, FcRn is responsible for the half-life of up to 21 days in circulation of an IgG molecule. Furthermore, IgG can bind to C1q component of the classical complement cascade and activate complement-dependent cytotoxicity (CDC) by forming transmembrane channels, membrane attack complex, resulting in osmotic lysis of the target cell [27].

\section{The Contribution of the Fc Glycan to IgG}

IgG Fc fragment is comprised of two domains of the constant heavy chain (Figure 1a, C $\gamma 2$ and $\mathrm{C} \gamma 3$ ). A key component of IgG is located at the conserved N-linked glycosylation site, asparagine-297 (N297), near the hinge region in the $\mathrm{C} \gamma 2$ domain (Figure 1a). X-ray crystallography studies of IgG Fc suggest that the glycans on N297 are concealed in the cavity between two C $\gamma 2$ domains $[28,29]$. The N-linked glycans influence the steric hindrance between the two heavy chains, maintaining the IgG Fc in an opened conformation [30]. Removal of glycans results in collapse of the heavy chains [30], ablating binding to Fc $\gamma$ Rs and C1q, and abrogating ADCC and CDC [31,32].

The glycans at N297 have a complex-type biantennary structure, comprising core heptasaccharides and variable extensions of monosaccharides, including an addition of fucose to core $\mathrm{N}$-acetylglucosamine (GlcNAc), GlcNAc to the bisecting mannose, galactose to GlcNAc on the biantennary arms, and terminal sialic acid (Figure 1b). As a consequence of variable extensions, the glycan is tremendously heterogeneous; in humans over 30 glycoforms on the single IgG heavy chain have been identified [27,33-35]. Pairing of different glycans on each IgG heavy chain further increases the diversity of IgG glycoforms. 
The majorities of human IgG Fc glycans are highly fucosylated ( $>92 \%)$ [35] and can be separated into three subsets as determined by the number of terminal galactose, IgG; G0F ( 35\%), G1F ( 35\%), and G2F $(\sim 16 \%)$ for the fucosylated glycans terminating in zero, one or two galactose, respectively. A small proportion of these IgG Fc glycans contains a bisecting GlcNAc ( $>11 \%)$. Only $5 \sim 10 \%$ of IgG Fc glycoforms are mono-sialylated. Furthermore, $<1 \%$ of IgG Fc glycoforms have two sialic acids [33,35-37]. These differential compositions of the $\mathrm{N}$-linked glycans determine the effector functions by altering the affinity of IgG to activating or inhibitory Fc $\gamma$ Rs [38].

\subsection{Pro-Inflammatory IgG Fc Glycans}

The core fucose plays a major role regulating the magnitude of ADCC. Fractionation using Lens culinaris agglutinin (LCA) lectin affinity chromatography showed that enhanced ADCC is associated with the low fucosylated IgG1 fraction. Conversely, the highly fucosylated IgG1 fraction showed reduced ADCC [39]. Overexpression of a1,6-fucosyltransferase (FUT8) in a hybridoma that produces low levels of fucosylated IgG1 (YB2/0) also decreased the ability of these antibodies to elicit ADCC [39]. Several expression systems have been used to produce afucosylated recombinant human $\mathrm{IgG}$, for example, Chinese hamster ovary (CHO) fucosyltransferase-deficient variant line (Lec13) [40] or mutant tobacco-related plant species Nicotiana benthamiana lacking plant-specific N-glycan residues [41,42]. Regardless of the expression systems, afucosylated IgG exhibited a marked increase (up to 50-fold) in binding affinity to human FcyRIIIA, NK cell-mediated ADCC, and antiviral activity measured by antibody-dependent cell-mediated virus inhibition (ADCVI) assays [40,41]. In vivo studies also showed that afucosylated IgG had an increased ADCC potency in an immunotherapy mouse model [16,43] and provided better antiviral protection when mice were challenged against lethal dose of virus [42]. The increased affinity is attributed to reduced steric hindrance from the loss of fucose, promoting increased glycan-glycan interactions between Fc $\gamma$ RIIIA and afucosylated Fc [44,45].

The addition of GlcNAc to the bisecting mannose by co-overexpressing the recombinant IgG1 and $\beta 1,4-N$-acetylglucosaminyltransferase III (GnTIII) in CHO cells also increased the binding affinity to FcyRIIIA and ADCC. However, the increase in affinity is modest when compared to afucosylated glycoforms, with enhancement of 10 - to 20 -fold [39,46,47].

Although several studies have showed that agalactosylated IgG has decreased CDC [48,49], other studies demonstrated that agalactosylated $\mathrm{IgG}$ activates the complement system by increasing binding to an activator of CDC, mannose-binding lectin (MBL) [50,51]. The increased MBL-binding in agalactosylated $\mathrm{IgG}$, however, did not translate into increased $\mathrm{CDC}$ in vivo, as no difference was observed between differentially galactosylated IgG in the knockout mice of MBL or C3 (a component in complement cascade) [50]. Furthermore, removal of the terminal galactose on IgG Fc glycans by sequential treatment of neuraminidase and galactosidase failed to alter the $\mathrm{A} / \mathrm{I}$ ratio and $\mathrm{ADCC}$ of IgG, or IgG-elicited inflammatory response in the mouse model of rheumatoid arthritis [50]. This strongly disputes a direct involvement of galactose in IgG-elicited pro-inflammatory activity. However, recent evidence suggests that agalactosylated IgG may have some roles in antiviral activity [52]. In HIV patients where the symptoms are controlled (i.e., high viral inhibition), the global pool of IgG shifted to agalactosylated glycoforms. Additionally, the agalactosylated IgG was associated with an increase in ADCVI, which may be explained by an increase binding to Fc $\gamma$ RIIIA; treatment of IgG with galactosidase was shown to have an increased binding to Fc $\gamma$ RIIIA beads [52]. 


\subsection{Anti-Inflammatory IgG Fc Glycans}

The addition of terminal galactose residues to the IgG Fc glycans can exhibit anti-inflammatory activity. A recent study showed that highly galactosylated IgG1 mediates anti-inflammatory activity by facilitating the association of the inhibitory receptor Fc $\gamma$ RIIB and a C-type lectin-like receptor dectin-1 suggesting a novel role for terminal galactose on $\mathrm{IgG}$ Fc glycans [53]. This association results in inhibition of $\mathrm{C} 5 \mathrm{a}$ receptor $(\mathrm{C} 5 \mathrm{aR})$-mediated inflammatory responses. The anti-inflammatory activity appears to be subclass specific, as highly galactosylated IgG2a failed to initiate such inhibition [53]. Further studies are needed to understand how highly galactosylated IgG1-immune complexes are formed in vivo and how the in vivo immune complexes facilitate the association of Fc $\gamma$ RIIB and dectin-1 to elicit anti-inflammation.

Several studies have suggested that terminal sialic acid residues on IgG Fc glycans mediates anti-inflammatory responses [54-58]. The addition of terminal sialic acid residues on IgG Fc glycans has been shown to greatly reduce ADCC in vivo and in vitro. This effect is independent of $\alpha 2,3-$ or $\alpha 2,6$-linkage, and is attributed to the decreased binding affinity of sialylated IgG for their respective canonical Fc $\gamma$ Rs $[54,55,59]$. The presence of terminal sialic acid, specifically, the $\alpha 2,6-$ and not the $\alpha 2,3-$ linkage, is indispensible in mediating the anti-inflammatory activity of $\operatorname{IgG}[54-56,58]$.

Intravenous gammaglobulin (IVIG) is a therapeutic preparation of monomeric IgG antibodies prepared from the plasma of tens of thousands of donors. It was developed as an antibody replacement therapy $(400-600 \mathrm{mg} / \mathrm{kg}$ ) for immunocompromised individuals unable to produce their own $\operatorname{IgG}$ antibodies. However, when administered at a high dose (1-2 g/kg), IVIG exhibits general anti-inflammatory properties, and is used at this dose to treat various diseases mainly associated with autoimmune settings, such as immunothrombocytopenia (ITP), multiple sclerosis, systemic lupus erythematosus (SLE), and chronic inflammatory demyelinating neuropathy [60-62].

Many mechanisms, including activities from both Fab and Fc portions of IgG molecule, have been suggested to underlie IVIG-elicited anti-inflammatory activity [15]. More recently, $\alpha 2,6$-sialylated IgG Fc were identified to play a key role in inducing anti-inflammatory activity of IVIG treatment in the rheumatoid arthritis [54,55], nephrotoxic nephritis [63] and ITP models [58]. Specifically, complete removal of N-linked glycans by PNGase F, or a more selective removal of terminal sialic acid by neuraminidase or $\alpha 2,3 / 2,6$ sialidase abolished IVIG protection in those autoimmune disease models $[54,55,58]$. However, no difference was observed when $\alpha 2,3$-sialic acid was removed using $\alpha 2,3$-sialidase [55]. The anti-inflammatory role of $\alpha 2,6$-sialylated IgG was further confirmed using the recombinant form to mimic the protective effect mediated by IVIG [55]. It is important to note that compared to Fc, Fab portion of human IgG is highly sialylated; $15-20 \%$ of human IgG has highly sialylated N-linked glycans on the Fab portion of human IgG [36]. Enrichment of sialylated IgG from intact IVIG by Sambucus nigra agglutinin (SNA) lectin fractionation predominantly yields IgG with sialic acid on the Fab portion and exhibits no anti-inflammatory activity when tested in the mouse ITP model $[64,65]$.

Little was known of the mechanism underlying sialylation-induced anti-inflammatory activity until recently, sialylated IgG was shown to require C-type lectins mouse SIGN-R1 (specific intracellular adhesion molecule-grabbing non-integrin R1) or the human orthologue DC-SIGN (dendritic-cell-specific ICAM-3 grabbing non-integrin). There is precedent for interactions between an 
immunoglobulin with C-type lectins, for example, $\operatorname{IgE}$ is known to engage a C-type lectin CD23. Importantly, a recent study showed remarked similarities between a model of DC-SIGN/sialylated-IgG-Fc complex with crystalized structure CD23/IgE-Fc complex [66]. It is known that binding of $\operatorname{IgE}$ to CD23 cannot be inhibited by monosaccharides [67] and thus the interaction is not via glycans but through protein-protein interaction. As mentioned above, sialylated IgG glycoform has reduced binding to their respective canonical Fc $\gamma$ Rs [54,55,59], suggesting a conformation change of IgG upon sialic acid addition to the Fc. This conformational change may explain the phenomenon of sialylated IgG binding to DC-SIGN and also the lack of competition between IgG and known ligands of the DC-SIGN carbohydrate recognition domain (CRD) [68]. Although conflicting results have been reported on the binding of sialylated IgG (or sialylated Fc) to DC-SIGN based on different ELISA binding assays $[57,66,68]$, data from in vivo experiments using SIGN-R1 ${ }^{-/}$ or humanized DC-SIGN mice demonstrated that DC-SIGN or SIGN-R1 are indispensible in sialylation-dependent anti-inflammatory activity of IVIG. It is possible that detection of the interaction between sialylated IgG Fc and DC-SIGN requires cell-based binding assays, as binding conditions established for high affinity ligands, including gp120, may not be appropriate to detect this specific protein-protein interaction [68]. Although, anti-tumour IgG recovered from melanoma patients bound DC-SIGN in a sialylation-dependent manner, as determined by an ELISA-based method [69].

Specifically, the protective effect of sialylated IVIG-derived Fc was abolished in SIGN-R1 $1^{-/}$mice and can be rescued in SIGN-R $1^{-/}$mice expressing DC-SIGN in the mouse model of rheumatoid arthritis [56,57]. Similar finding was observed using SIGN-R1 blocking antibody in the mouse model of ITP [58]. Interestingly, in the mouse model of rheumatoid arthritis, the anti-inflammatory activity mediated by sialylated IVIG-derived $\mathrm{Fc}$ was shown to be $\mathrm{T}_{\mathrm{H}} 2$ pathway-dependent. On the other hand, in the mouse model of ITP, $\mathrm{T}_{\mathrm{H}} 2$ pathway does not seem to be involved in the sialylation-dependent protection mediated by IVIG [58]. This suggests that differential cytokine milieu may be responsible for the sialylation-dependent pathway of IVIG immunomodulation in different diseases.

IVIG may also recruit pathways independent of sialylated IgG to initiate anti-inflammation. Studies showed that desialylation of IVIG by neuraminidase failed to abolish the protective effect of IVIG in a mouse ITP model [65] and in an in vitro assay of human whole blood stimulation by lipopolysaccharides and phytohaemagglutinin (PHA) [70]. Additionally, compared to IVIG, enriched sialylated IgG Fc did not further inhibit PHA-stimulated cytokine secretion from human whole blood [70]. Alternative mechanisms have been suggested to underlie the suppression of inflammation by IVIG, including saturation of FcRn, competition with Fc $\gamma$ Rs, or anti-idiotypic antibodies [15].

It is unquestionable that N-linked IgG Fc glycans are important in determining distinct effector functions. Recently, a study using solution Nuclear Magnetic Resonance (NMR), which allows characterization of conformationally labile systems such as polysaccharides, revealed that the glycan on IgG Fc are more exposed structurally than previously shown [71]. This technique may provide detailed characterization of the interaction between glycans on IgG Fc and the respective receptor and give further insight into the immunomodulatory role of $\operatorname{IgG}$ Fc glycans. Furthermore, the ability of each component on the Fc glycans to fine-tune the strength and specificity of the signals can be fully exploited for designing therapeutic antibodies. Indeed, as ADCC is one of the crucial mechanisms in killing tumour cells, the recently developed $\operatorname{IgG}$ antibodies for cancer therapy are glycoengineered to eliminate fucose on the Fc glycans in order to improve the efficacy in killing tumours [43,72,73] (Figure 1c). 


\section{IgG Glycovariants under Physiological and Patho-Physiological Conditions}

The glycosylation pattern of human serum IgG varies markedly depending on the physiological status of individuals. Studies have shown that the level of galactosylated and sialylated serum IgG increases during pregnancy and decreases postpartum [74,75]. Similarly for aging, galactosylation levels on IgG have been shown to increase from birth to the age of 25 years and then decrease subsequently. The level of sialylated IgG was also shown to decrease during aging. Furthermore, the decrease in galactosylation and sialylation was associated in particular, in females and not males, suggesting sexual dimorphism may also play a role [76,77].

IgG glycosylation is also altered in diseased states. Compared to healthy individuals, there is a marked increase of agalactosylated and asialylated serum IgG in individuals with autoimmune diseases [51,78-81], infectious diseases [81,82] and tumours [83,84]. It is still unclear whether the disease affects the glycosylation of all or just antigen-specific IgG, which then contribute to the overall change observed in total IgG. Studies have shown that antigen-specific IgG involved in the pathogenesis of some diseases are agalactosylated and asialylated. For example, anti-citrullinated protein antibodies in rheumatoid arthritis and anti-proteinase 3 antibodies in Wegener's granulomatosis [80,85]. A study further showed that the glycosylation pattern of antigen-specific IgG differed from the total IgG; the pattern also differed between serum and the site of inflammation, for example, synovial fluid [85]. Thus, the glycosylation pattern of antigen-specific IgG may be locally tailored by the inflammatory microenvironment to shape the effector functions. Importantly, the altered glycosylation pattern observed in the studies of patients with rheumatoid arthritis and Wegener's granulomatosis showed a correlation between reduced galactosylated and sialylated IgG and an increase in disease activity. Conversely, an increase in galactosylated and sialylated IgG was associated with disease remission $[79,80]$. As mentioned above, during pregnancy, the glycosylation pattern of $\operatorname{IgG}$ fluctuates; the increase in galactosylation and sialylation strongly correlates with the remission in pregnant rheumatoid arthritis patients and the reverse is true post-partum [74,75]. It is still unclear whether galactosylation, sialylation, or other factors are involved in improved rheumatoid arthritis; more work will be required to fully understand the role they have in patients with alleviated symptoms.

In contrast to the apparent differences observed in the levels of galactosylation and sialylation in pregnant women and rheumatoid arthritis patients, it is still unclear whether the level of fucose or bisecting GlcNAc on IgG Fc glycans alters in these individuals. In rheumatoid arthritis patients, although a study reported no difference in fucosylated IgG [86], another has reported an increase in fucosylation [87]. Using a mouse model, repeated immunization of mice was shown to sequentially increase fucosylation on antigen-specific IgG based on lectin-ELISA [88], supporting an increase in fucosylated $\mathrm{IgG}$ in an inflammatory setting. In rheumatoid arthritis patients, a separate study reported a $20 \%$ increase in GlcNAc [86], however, it did not differentiate between antenna or bisecting GlcNAc, thus the reported increase in GlcNAc could also represent the exposure of antenna GlcNAc from the decrease in galactosylation. In contrast to the association of galactose and sialic acid with disease remission during pregnancy of rheumatoid arthritis patients, these patients were reported to have unaltered levels of fucose or bisecting GlcNAc on IgG Fc $[74,86]$.

To date, little is known of the causal link between changes in glycan compositions on IgG Fc during various physiological and pathophysiological conditions. It has been reported that the environmental 
factors could modulate glycosylation of IgG Fc [89]; in vitro stimulation of human B cells with a natural metabolite of vitamin A, all-trans retinoic acid, reduced the levels of galactosylation and sialylation on IgG Fc. In contrast, stimulation with T-cell secreted immune-stimulating cytokine, IL-21, or bacterial DNA-mimic $\mathrm{CpG}$, increases the galactosylated and sialylated IgG [89]. However, in the same study, no differences were observed in the IgG Fc glycosylation pattern stimulated by the pro-inflammatory cytokines involved in rheumatoid arthritis, including IL- 6 or TNF- $\alpha$. Interestingly, some reports have shown that combined treatment of infliximab (anti-TNF- $\alpha$ neutralizing antibody) and methotrexate in rheumatoid arthritis patients increased the galactosylated IgG, indicating that TNF- $\alpha$ may be involved in regulating IgG glycosylation pattern [90,91].

Although some environmental factors can influence the IgG glycosylation patterns, the identity and the role of downstream targets remain to be elucidated. As the composition of IgG Fc glycans is dependent on the regulation of glycosyltransferases and glycosidases (Figure 1b), it is speculated that the expression and activity of these enzymes are differentially regulated in response to stimulation of environmental factors. Indeed, several studies showed that rheumatoid arthritis patients have a decreased galactosyltransferase activity in B cells compared to controls [92-94], consistent with an increase in agalactosylated $\mathrm{IgG}$. As the mRNA and protein expression of $\beta 1,4$-galactosyltransferase were not shown to change in B cells of rheumatoid arthritis patients, the decrease may be explained by the differential expression of serum $\beta 1,4$-galactosyltransferase isoforms in rheumatoid arthritis patients [95-97]. Alternatively, it has been suggested that polyclonal B cells express different levels of $\beta 1,4$-galactosyltransferase, and the pathological conditions of RA might select for clonal expansion of B cells expressing low levels of $\beta 1,4$-galactotransferase [98].

The enzyme crucial for the addition of $\alpha 2,6$-sialic acid to glycan termini is $\beta$-galactoside $\alpha 2,6$-sialyltransferase 1 (ST6Gal-1). Using a mouse model, it has been reported that ST6Gal-1 deletion results in more severe pulmonary inflammation [99], consistent with the importance of sialic acid in anti-inflammation [54,56]. Recently, ST6Gal-1 driven by liver-specific promoter P1 in the systemic circulation was shown to be important for the addition of $\alpha 2,6$-sialic acid on the serum IgG Fc glycan [100]. As the P1 promoter does not induce the expression of ST6Gal-1 in B cells, the reduction in serum sialylated IgG in P1-deficient mice is attributed to the decreases in circulatory ST6Gal-1 [100].

Thus, it has been established that IgG glycosylation patterns differ under various physiological and pathophysiological conditions. However, the specific factors that control IgG glycosylation are not clear, and under current investigation. Importantly, defining the regulation of IgG glycan may represent a novel therapeutic strategy for cancer and autoimmune diseases.

\section{The Role of Glycans in IgE Biology}

Perhaps the most well known IgE-mediated effector function is initiation of type I immediate hypersensitivity. Responsible for both allergic responses and anaphylaxis, this hypersensitivity reaction is triggered by cross-linking of IgE that are already bound to the high-affinity FceRI $\left(\mathrm{K}_{d}=10^{-10} \mathrm{M}\right)$ on mast cells and basophils [101]. The ensuing activation leads to degranulation and secretion of pharmacologically active substances such as histamine, leukotriene, and prostaglandin. This results in vasodilation, smooth muscle contraction, and an increase in vasopermeability. Additionally, IgE binds to the low-affinity FceRII $\left(\mathrm{K}_{\mathrm{d}}=10^{-6} \mathrm{M}\right)$ to regulate $\mathrm{IgE}$ synthesis and facilitate antigen presentation of B cells to $\mathrm{T}$ cells, resulting in epitope spreading [101,102]. 
In comparison to $\mathrm{IgG}$, less is known as to the role glycans play in mediating IgE effector functions. As IgG Fc glycans are key to IgG-mediated effector functions, it is possible that Fc glycans would also be important for immunoglobulins of other classes. Interestingly, among all immunoglobulin classes, $\mathrm{IgG}$ is the least glycosylated. There is one conserved $\mathrm{N}$-linked glycosylation site on each heavy chain and the total weight of glycosylation on the $\gamma$ heavy chains contributes to $\sim 2-3 \%$ of the molecular weight of IgG [33]. On the other hand, IgE is heavily glycosylated; there are six complex-type biantennary (N140, N168, N218, N265, N371, N383) and one oligomannose-type (N394) conserved N-linked glycosylation sites on the constant region of each heavy chain. The total glycan weight on $\varepsilon$ heavy chains contributes to $\sim 12 \%$ of the molecular weight of IgE [103] (Figure 2).

Figure 2. Schematic representation of the human $\operatorname{IgE}$ structure and glycan composition. (A) IgE structure. IgE protein is comprised of two heavy chains (black outline) and two light chains (blue outline). Each $\operatorname{IgE}$ heavy chain has the variable region $\left(\mathrm{V}_{\mathrm{H}}\right)$ and the constant region containing four domains (CE1-4). Compared to $\mathrm{IgG}$, instead of the hinge region, $\operatorname{IgE}$ has an extra domain. Each light chain has variable $\left(\mathrm{V}_{\mathrm{L}}\right)$ and constant regions $\left(\mathrm{C}_{\mathrm{L}}\right)$. IgE molecule can be divided into antigen-binding fragment (Fab; empty ovals) and fragment crystallizable region ( $\mathrm{Fc}$; pink ovals). The red and blue dots represent N-linked glycans of complex-type and oligomannose-type, respectively. (B) Composition of the oligomannose-type N-linked glycan on IgE N394. The glycan typically consists of 2 GlcNAc with 5 branching mannoses [104], not in order though a range of 4-8 has been reported [33]. Abbreviations: N, GlcNAc; M, mannose.

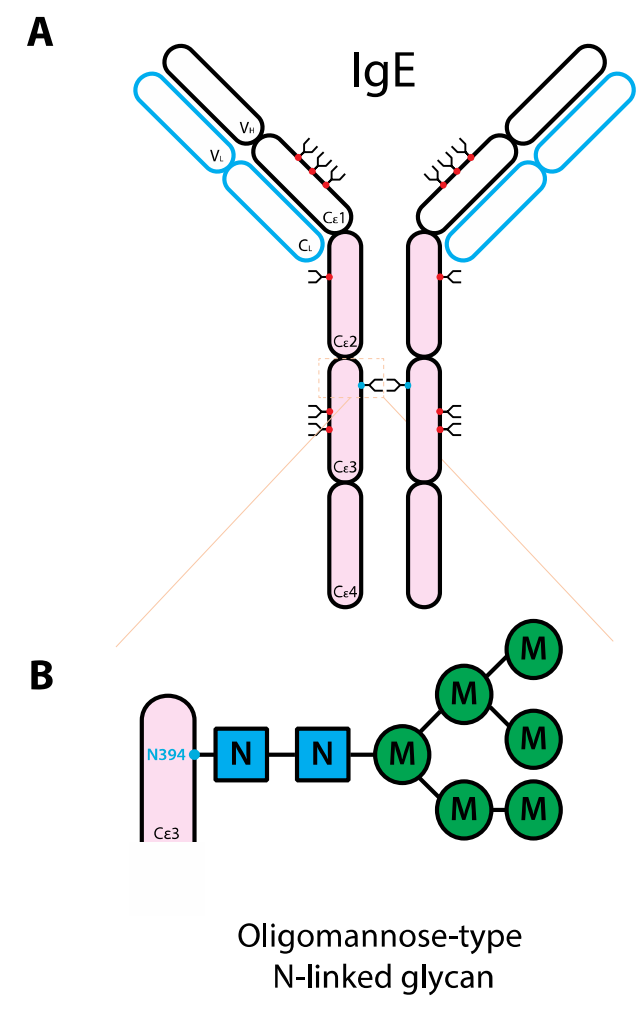

Although several studies have examined the role of IgE Fc glycans in interacting with FceRI, the results remain inconclusive. Removal of IgE Fc glycans by the combined enzymatic treatment of neuraminidase, Endo F, and PNGase F [105] or site directed mutagenesis of both N265 and N371 [106] 
neither affected the binding to FceRI nor the passive sensitization of basophil in releasing histamine. However, this finding is not supported by others; binding of IgE molecules or IgE-Fc fragments to FceRI was shown to significantly reduce upon PNGase F treatment [107,108]. Mutagenesis of the conserved N394 site, which corresponds to N297 on IgG Fc [109], also reduced the binding to FceRI [110]. Thus, further studies will be required confirm the role of $\operatorname{IgE}$ in binding to FceRI.

Interestingly, unlike Fc $\gamma$ Rs or FceRI, FceRII also known as CD23, is not part of the immunoglobulin superfamily; it is a C-type lectin. As IgE is heavily glycosylated, it was initially speculated that the glycans on IgE are responsible for binding to FceRII. However, it was demonstrated that instead of reduced binding as predicted, deglycosylated IgE had an increased binding to FceRII on the B cells [111]. In line with this, double mutation of N265Q and N371Q on IgE Fc also had a higher affinity than the respective wild-type to FceRII [106]. This suggests that IgE glycans may alter FceRII-mediated effector responses but not as a result of carbohydrate binding. This is further supported by another study where high concentrations of an array of mono- or disaccharides were unable to inhibit the binding of IgE to FceRII [67], indicating that the binding is not mediated via carbohydrate binding but instead through protein-protein interaction. In addition to FceRs, many other proteins also bind to IgE, for example, $\mathrm{CD} 21$, galectin-3, and surfactant protein $\mathrm{D}$. These interactions may have a role in regulating $\operatorname{IgE}$ responses in allergy and asthma [33,101,112].

In summary, existing studies on IgE glycosylation are in favor of N-linked Fc glycans having a minimal role on binding to FceRI. The finding that the loss of glycans on IgE increases binding to FceRII suggests that glycans may have an attenuative role in mediating FceRII-mediated effector functions, similar to the effect of polysialylation on Neural Cell Adhesion Molecule (NCAM) [113].

\section{The Role of Glycans in IgA Biology}

IgA is most well known for its role in mucosal immunity by mediating immune exclusion, a process where adhesion of pathogens on epithelium is prevented. Furthermore, IgA can modulate inflammatory activity as a result of activating or inhibitory signals initiated through FcaRI (CD89) [114]. The diversity of IgA-mediated effector functions is partly attributed to its forms. Human IgA mainly exists in three forms, namely monomer, dimer, and secretory. Secretory $\operatorname{IgA}$ (SIgA) is important for immune exclusion. Additionally, IgA in immune complexes triggers activating ITAM-Syk pathway resulting in pro-inflammatory activity such as ADCC and phagocytosis. On the other hand, monomeric IgA was reported to dampen the inflammatory signal by partially phosphorylate the ITAM on FcR $\gamma$ that results in recruitment of SHP-1 phosphatase [115].

In addition to forms, human $\operatorname{IgA}$ exists in two isotypes: $\operatorname{IgA} 1$ and $\operatorname{Ig} \mathrm{A} 2$. $\operatorname{Ig} \mathrm{A} 2$ can be further divided into two subisotypes: $\operatorname{IgA} 2 \mathrm{~m}(1)$ and $\operatorname{IgA} 2 \mathrm{~m}(2)$. In human serum, $\operatorname{IgA} 1$ accounts for $\sim 85 \%$ of total $\operatorname{IgA}$ and is predominantly in monomeric form whereas mucosal IgA primarily exists in polymeric form including dimeric and secretory form. Compared to IgG where the only glycosylation site is conserved across the isotypes, the sites in IgA vary between isotypes and subisotypes. IgA1 has two N-linked complex-type glycosylation sites at N263 on the Ca2 domain and N459 on the tailpiece, and nine $O$-linked glycosylation sites in the hinge region (Figure 3a). In general, fewer than six $O$-linked sites are glycosylated [116]. IgA2m(2) has five N-linked glycosylation sites (N166, N211, N263, N337, N459) whereas $\operatorname{IgA} 2 \mathrm{~m}(1)$ has similar sites as $\operatorname{IgA} 2 \mathrm{~m}(2)$ without $\mathrm{N} 211[33,115]$. The importance of $\mathrm{N}$-linked glycans on IgA Fc is currently unclear. One study showed that neither of the N-linked glycans 
on IgA1 Fc seem to be critical for Fc $\alpha$ RI binding; the binding of IgA1 to Fc $\alpha$ RI was unaltered by N263A mutation or deletion of C-terminal tailpiece containing N459 [117]. However, another study reported that IgA1 binding to Fc $\alpha$ RI was abolished when the asparagine residue on the $\mathrm{C} \alpha 2$ domain was mutated to glutamine (Q) [118]. Future studies are required to clarify whether N-linked glycans on IgA1 Fc modifies FcaRI binding and the subsequent effector functions. Interestingly, patients with an autoimmune disease that debilitates the exocrine glands, namely primary Sjögren's syndrome, were shown to have an increased level of sialylated monomeric serum IgA1 compared to healthy controls [119]. The addition of sialic acid was suggested to hinder the clearance of IgA, resulting in excess amount of serum $\operatorname{IgA}$ and thus the immune complexes.

Figure 3. Schematic representation of the human IgA1 structure and glycan composition. (a) IgA1 structure. IgA1 protein is comprised of two heavy chains (black outline) and two light chains (blue outline). Each IgA heavy chain is comprised of the variable region $\left(\mathrm{V}_{\mathrm{H}}\right)$ and the constant region containing three domains (C $\alpha 1-3)$. The line between $\mathrm{C} \alpha 1$ and $\mathrm{C} \alpha 2$ represents the hinge region. Each light chain has variable $\left(V_{L}\right)$ and constant regions $\left(C_{L}\right)$. IgA1 molecule can be divided into antigen-binding fragment (Fab; empty ovals) and fragment crystallizable region ( $\mathrm{Fc}$; pink ovals). The red and green dots represent the complex-type N-linked and O-linked glycans, respectively. (b) Composition of O-linked glycans on IgA1. The glycans can have six different variants (i-vi). Abbreviations: N, GlcNAc; G, galactose; S, sialic acid.

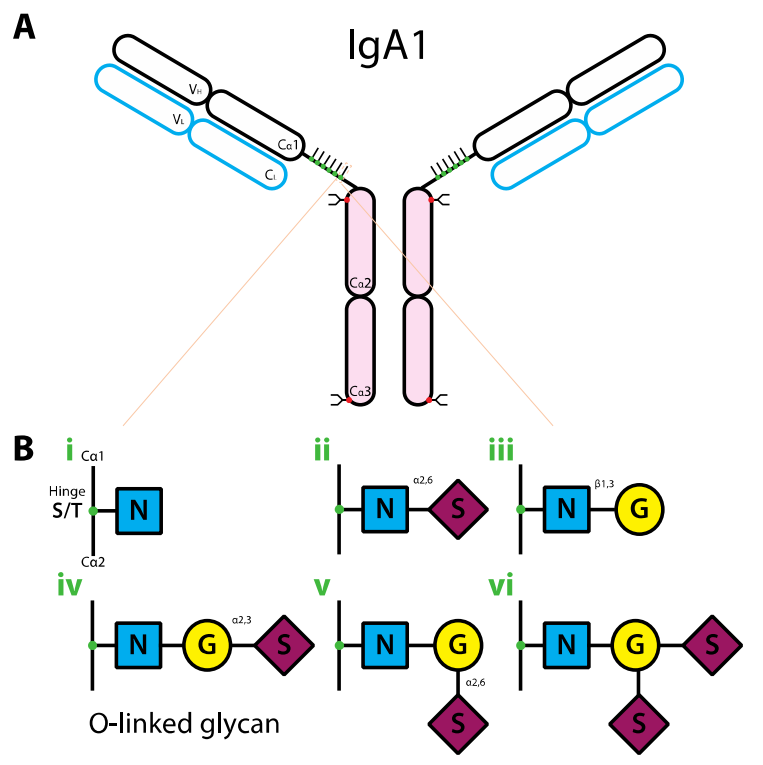

In comparison with $\mathrm{N}$-linked glycans, O-linked glycans on the IgA hinge region appear to be important. There are six IgA1 O-linked glycovariants [116,117] (Figure 3b) and the predominant forms were shown to be the glycovariants with at least the core GlcNAc and $\beta 1,3$-linked galactose [117] (Figure 3biii-vi). Aberration in O-linked glycan composition on IgA has been linked to $\operatorname{IgA}$ nephropathy. Indeed, peripheral blood cells from IgA nephropathy patients were shown to produce primarily agalactosylated O-linked IgA1 glycans with either terminal or sialylated GlcNAc compared to controls [120] (Figure 3bi-ii). The agalactosylated IgA acts as an autoantigen that gets subsequently targeted by glycan-specific IgG and/or IgA1 autoantibodies, leading to IgA-IgG or IgA-IgA immune 
complexes [121]. The level of these immune complexes has been reported to correlate with the disease activity [122], however, the pathogenesis of IgA nephropathy caused by these immune complexes is not completely understood. It is known that the increase in serum IgA-containing immune complexes is likely to reduce hepatic clearance of IgA, thus promoting an increase in renal deposits. The eventual renal injury is thought to be partly caused by an increase in cytokines or growth factors produced by the IgA-containing renal deposits $[116,123]$. Alteration of either $\mathrm{N}$ - or O-linked glycans on IgA appeared to be partly responsible for the increased level of IgA-containing immune complexes and possibly the development of autoimmune diseases.

\section{The Role of Glycans in IgM Biology}

$\operatorname{IgM}$ is the immunoglobulin class associated with primary immune response, as it is the first immunoglobulin produced in response to antigen exposure. Glycan analysis showed that IgM is highly glycosylated like IgE, it has five N-linked glycosylation sites including three complex- and two oligomannose-type [124] (Figure 4). Although GlcNAc-terminating IgM glycoforms bind MBL, the binding is lost when $\operatorname{IgM}$ is bound to antigen, suggesting antigen-bound $\operatorname{IgM}$ does not trigger complement pathway. The binding of MBL to IgM may facilitate the removal of IgM aggregates by opsonisation [124].

Figure 4. Schematic representation of the human $\operatorname{IgM}$ structure. IgM protein is comprised of two heavy chains (black outline) and two light chains (blue outline). Similar to IgE, each IgM heavy chain has the variable region $\left(\mathrm{V}_{\mathrm{H}}\right)$ and the constant region containing 4 domains $(\mathrm{C} \mu 1-4)$. Each light chain has variable $\left(\mathrm{V}_{\mathrm{L}}\right)$ and constant regions $\left(\mathrm{C}_{\mathrm{L}}\right)$. IgM molecule can be divided into antigen-binding fragment (Fab; empty ovals) and fragment crystallizable region (Fc; pink ovals). The red and blue dots represent N-linked glycans of complex-type and oligomannose-type, respectively. The black lines represent inter-chain disulfide bridges. Typically, IgM forms a pentamer or hexamer in circulation and only the pentameric form has a single $\mathrm{J}$ chain.

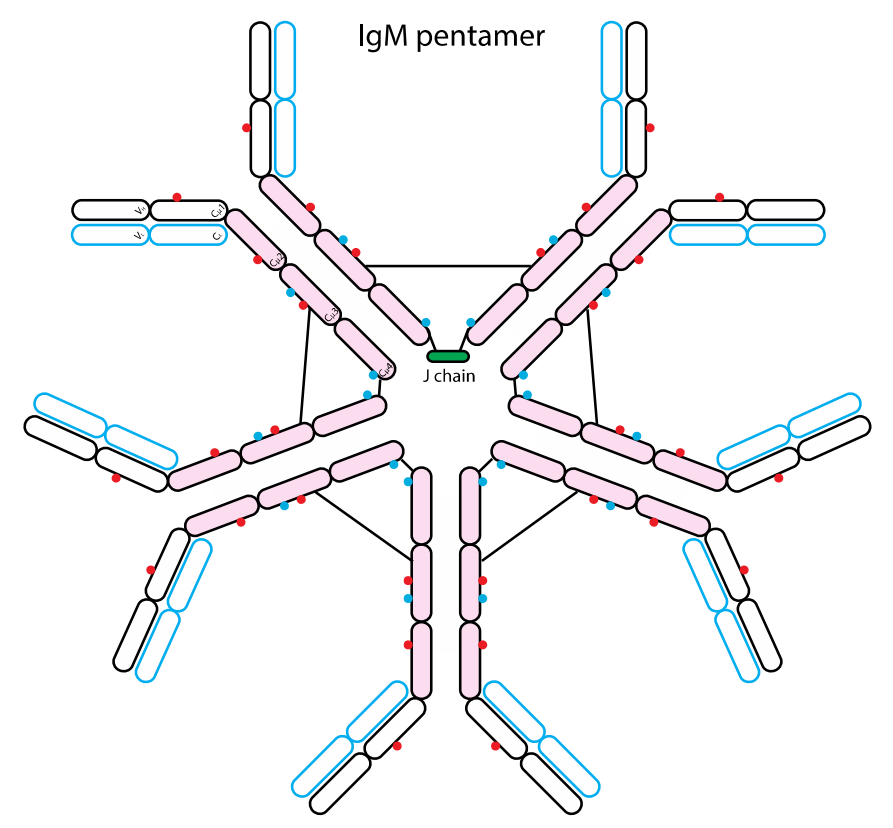




\section{Summary}

In conclusion, minor modification of glycans on the Fc portion of IgG can have significant impact on the receptor binding and the effector functions. It is remarkable that the presence of a single sugar on IgG Fc glycans significantly manipulates the effector functions. The addition of fucose to promote ADCC is a powerful tool when designing therapeutic antibodies for cancer. Furthermore, the ability of terminal sialic acid to completely switch IgG-mediated effector functions from pro- to anti-inflammatory activity opens a novel avenue for future design of anti-inflammatory therapeutic antibodies (Figure 1c). The role of individual sugar modification on other immunoglobulin isotypes requires further investigation. Combining glycan modification with the knowledge of antibody isotypes and Fc $\gamma$ Rs polymorphisms of the patients, the future of personalized therapeutic antibodies with maximal efficacy for individuals awaits.

\section{Acknowledgment}

We thank Maya Kitaoka for careful reading and helpful comments of the manuscript.

\section{Conflict of Interest}

The authors declare no conflict of interest.

\section{References}

1. Chang, T.W.; Wu, P.C.; Hsu, C.L.; Hung, A.F. Anti-IgE Antibodies for the treatment of IgE-mediated allergic diseases. Adv Immunol. 2007, 93, 63-119.

2. Kempeni, J. Preliminary results of early clinical trials with the fully human anti-TNF $\alpha$ monoclonal antibody D2E7. Ann. Rheum. Dis. 1999, 58, I70-I72.

3. Maini, R.; St Clair, E.W.; Breedveld, F.; Furst, D.; Kalden, J.; Weisman, M.; Smolen, J.; Emery, P.; Harriman, G.; Feldmann, M.; et al. Infliximab (chimeric anti-tumour necrosis factor $\alpha$ monoclonal antibody) versus placebo in rheumatoid arthritis patients receiving concomitant methotrexate: A randomised phase III trial. Lancet 1999, 354, 1932-1939.

4. Targan, S.R.S.; Hanauer, S.B.S.; van Deventer, S.J.S.; Mayer, L.L.; Present, D.H.D.; Braakman, T.T.; DeWoody, K.L.K.; Schaible, T.F.T.; Rutgeerts, P.J.P. A short-term study of chimeric monoclonal antibody cA2 to tumor necrosis factor alpha for Crohn“s disease. Crohn"s Disease cA2 Study Group. N. Engl. J. Med. 1997, 337, 1029-1035.

5. Hudis, C.A. Trastuzumab-Mechanism of action and use in clinical practice. N. Engl. J. Med. 2007, 357, 39-51.

6. Maloney, D.G.; Grillo-López, A.J.; White, C.A.; Bodkin, D.; Schilder, R.J.; Neidhart, J.A.; Janakiraman, N.; Foon, K.A.; Liles, T.M.; Dallaire, B.K.; et al. IDEC-C2B8 (Rituximab) anti-CD20 monoclonal antibody therapy in patients with relapsed low-grade non-Hodgkin's lymphoma. Blood 1997, 90, 2188-2195.

7. Scott, A.M.; Wolchok, J.D.; Old, L.J. Antibody therapy of cancer. Nat. Rev. Cancer 2012, 12, 278-287. 
8. Harris, L.J.L.; Larson, S.B.S.; Hasel, K.W.K.; Day, J.J.; Greenwood, A.A.; McPherson, A.A. The three-dimensional structure of an intact monoclonal antibody for canine lymphoma. Nature 1992, 360, 369-372.

9. Schroeder, H.W., Jr, Cavacini, L. Structure and function of immunoglobulins. J. Allergy Clin. Immunol. 2010, 125, S41-S52.

10. Gould, H.J.; Sutton, B.J.; Beavil, A.J.; Beavil, R.L.; McCloskey, N.; Coker, H.A.; Fear, D.; Smurthwaite, L. The biology of IGE and the basis of allergic disease. Annu. Rev. Immunol. 2003, 21, 579-628.

11. Daëron, M. Fc receptor biology. Annu. Rev. Immunol. 1997, 15, $203-234$.

12. Takai, T. Roles of Fc receptors in autoimmunity. Nat. Rev. Immunol. 2002, 2, 580-592.

13. Nimmerjahn, F.; Ravetch, J.V. Fc $\gamma$ receptors as regulators of immune responses. Nat. Rev. Immunol. 2008, 8, 34-47.

14. Nimmerjahn, F.; Ravetch, J.V. Antibody mediated modulation of immune responses. Immunol. Rev. 2010, 236, 265-275.

15. Schwab, I.; Nimmerjahn, F. Intravenous immunoglobulin therapy: How does IgG modulate the immune system? Nat. Rev. Immunol. 2013, 13, 176-189.

16. Nimmerjahn, F.; Ravetch, J.V. Divergent immunoglobulin g subclass activity through selective Fc receptor binding. Science 2005, 310, 1510-1512.

17. Wu, J.; Edberg, J.C.; Redecha, P.B.; Bansal, V.; Guyre, P.M.; Coleman, K.; Salmon, J.E.; Kimberly, R.P. A novel polymorphism of FcgammaRIIIa (CD16) alters receptor function and predisposes to autoimmune disease. J. Clin. Invest. 1997, 100, 1059-1070.

18. Shields, R.L.; Namenuk, A.K.; Hong, K.; Meng, Y.G.; Rae, J.; Briggs, J.; Xie, D.; Lai, J.; Stadlen, A.; Li, B.; et al. High resolution mapping of the binding site on human IgG1 for Fc gamma RI, Fc gamma RII, Fc gamma RIII, and FcRn and design of IgG1 variants with improved binding to the Fc gamma R. J. Biol. Chem. 2001, 276, 6591-6604.

19. Koene, H.R.H.; Kleijer, M.M.; Algra, J.J.; Roos, D.D.; von dem Borne, A.E.A.; de Haas, M.M. Fc gammaRIIIa-158V/F polymorphism influences the binding of IgG by natural killer cell Fc gammaRIIIa, independently of the Fc gammaRIIIa-48L/R/H phenotype. Blood 1997, 90, 1109-1114.

20. Warmerdam, P.A.P.; van de Winkel, J.G.J.; Vlug, A.A.; Westerdaal, N.A.N.; Capel, P.J.P. A single amino acid in the second Ig-like domain of the human Fc gamma receptor II is critical for human IgG2 binding. J. Immunol. 1991, 147, 1338-1343.

21. Parren, P.W.; Warmerdam, P.A.; Boeije, L.C.; Arts, J.; Westerdaal, N.A.; Vlug, A.; Capel, P.J.; Aarden, L.A.; van de Winkel, J.G. On the interaction of IgG subclasses with the low affinity Fc gamma RIIa (CD32) on human monocytes, neutrophils, and platelets. Analysis of a functional polymorphism to human IgG2. J. Clin. Invest. 1992, 90, 1537-1546.

22. Musolino, A.; Naldi, N.; Bortesi, B.; Pezzuolo, D.; Capelletti, M.; Missale, G.; Laccabue, D.; Zerbini, A.; Camisa, R.; Bisagni, G.; et al. Immunoglobulin G fragment $\mathrm{C}$ receptor polymorphisms and clinical efficacy of trastuzumab-based therapy in patients with HER-2/neu-positive metastatic breast cancer. J. Clin. Oncol. 2008, 26, 1789-1796. 
23. Weng, W.-K.W.; Levy, R.R. Two immunoglobulin G fragment C receptor polymorphisms independently predict response to rituximab in patients with follicular lymphoma. J. Clin. Oncol. 2003, 21, 3940-3947.

24. Tamura, K.; Shimizu, C.; Hojo, T.; Akashi-Tanaka, S.; Kinoshita, T.; Yonemori, K.; Kouno, T.; Katsumata, N.; Ando, M.; Aogi, K.; et al. Fc $\gamma$ R2A and 3A polymorphisms predict clinical outcome of trastuzumab in both neoadjuvant and metastatic settings in patients with HER2-positive breast cancer. Ann. Oncol. 2011, 22, 1302-1307.

25. Bibeau, F.; Lopez-Crapez, E.; Di Fiore, F.; Thezenas, S.; Ychou, M.; Blanchard, F.; Lamy, A.; Penault-Llorca, F.; Frebourg, T.; Michel, P.; et al. Impact of Fc RIIa-Fc RIIIa Polymorphisms and KRAS Mutations on the Clinical Outcome of Patients With Metastatic Colorectal Cancer Treated With Cetuximab Plus Irinotecan. J. Clin. Oncol. 2009, 27, 1122-1129.

26. Kuo, T.T.; Aveson, V.G. Neonatal Fc receptor and IgG-based therapeutics. MAbs 2011, 3, 422-430.

27. Jefferis, R.R. Isotype and glycoform selection for antibody therapeutics. Arch. Biochem. Biophys. 2012, 526, 159-166.

28. Idusogie, E.E.E.; Presta, L.G.L.; Gazzano-Santoro, H.H.; Totpal, K.K.; Wong, P.Y.P.; Ultsch, M.M.; Meng, Y.G.Y.; Mulkerrin, M.G.M. Mapping of the C1q binding site on rituxan, a chimeric antibody with a human IgG1 Fc. J. Immunol. 2000, 164, 4178-4184.

29. Deisenhofer, J. Crystallographic refinement and atomic models of a human Fe fragment and its complex with fragment B of protein A from Staphylococcus aureus at 2.9-and 2.8-. ANG. resolution. Biochemistry 1981, 20, 2361-2370.

30. Feige, M.J.; Nath, S.; Catharino, S.R.; Weinfurtner, D.; Steinbacher, S.; Buchner, J. Structure of the Murine Unglycosylated IgG1 Fc Fragment. J. Mol. Biol. 2009, 391, 599-608.

31. Jefferis, R.R.; Lund, J.J. Interaction sites on human IgG-Fc for FcgammaR: Current models. Immunol. Lett. 2002, 82, 57-65.

32. Jefferis, R. The glycosylation of antibody molecules: Functional significance. Glycoconjug. $J$. 1993, 10, 358-361.

33. Arnold, J.N.J.; Wormald, M.R.M.; Sim, R.B.R.; Rudd, P.M.P.; Dwek, R.A.R. The impact of glycosylation on the biological function and structure of human immunoglobulins. Immunology 2007, 25, 21-50.

34. Routier, F.H.; Hounsell, E.F.; Rudd, P.M.; Takahashi, N.; Bond, A.; Hay, F.C.; Alavi, A.; Axford, J.S.; Jefferis, R. Quantitation of the oligosaccharides of human serum IgG from patients with rheumatoid arthritis: A critical evaluation of different methods. J. Immunol. Methods 1998, 213, 113-130.

35. Zauner, G.; Selman, M.H.J.; Bondt, A.; Rombouts, Y.; Blank, D.; Deelder, A.M.; Wuhrer, M. Glycoproteomic analysis of antibodies. Mol. Cell. Proteomics 2013, 12, 856-865.

36. Stadlmann, J.; Weber, A.; Pabst, M.; Anderle, H.; Kunert, R.; Ehrlich, H.; Peter Schwarz, H.; Altmann, F. A close look at human IgG sialylation and subclass distribution after lectin fractionation. Proteomics 2009, 9, 4143-4153.

37. Wuhrer, M.; Stam, J.C.; van de Geijn, F.E.; Koeleman, C.A.M.; Verrips, C.T.; Dolhain, R.J.E.M.; Hokke, C.H.; Deelder, A.M. Glycosylation profiling of immunoglobulin G (IgG) subclasses from human serum. Proteomics 2007, 7, 4070-4081. 
38. Anthony, R.M.; Wermeling, F.; Ravetch, J.V. Novel roles for the IgG Fc glycan. Ann. NY Acad. Sci. 2012, 1253, 170-180.

39. Shinkawa, T.T.; Nakamura, K.K.; Yamane, N.N.; Shoji-Hosaka, E.E.; Kanda, Y.Y.; Sakurada, M.M.; Uchida, K.K.; Anazawa, H.H.; Satoh, M.M.; Yamasaki, M.M.; et al. The absence of fucose but not the presence of galactose or bisecting $\mathrm{N}$-acetylglucosamine of human IgG1 complex-type oligosaccharides shows the critical role of enhancing antibody-dependent cellular cytotoxicity. J. Biol. Chem. 2003, 278, 3466-3473.

40. Shields, R.L.; Lai, J.; Keck, R.; O'Connell, L.Y.; Hong, K.; Meng, Y.G.; Weikert, S.H.A.; Presta, L.G. Lack of fucose on human IgG1 N-linked oligosaccharide improves binding to human Fcgamma RIII and antibody-dependent cellular toxicity. J. Biol. Chem. 2002, 277, 26733-26740.

41. Forthal, D.N.; Gach, J.S.; Landucci, G.; Jez, J.; Strasser, R.; Kunert, R.; Steinkellner, H. Fc-glycosylation influences $\mathrm{Fc} \gamma$ receptor binding and cell-mediated anti-HIV activity of monoclonal antibody 2G12. J. Immunol. 2010, 185, 6876-6882.

42. Zeitlin, L.L.; Pettitt, J.J.; Scully, C.C.; Bohorova, N.N.; Do, D.K.; Pauly, M.M.; Hiatt, A.A.; Ngo, L.L.; Steinkellner, H.H.; Whaley, K.J.K.; et al. Enhanced potency of a fucose-free monoclonal antibody being developed as an Ebola virus immunoprotectant. Proc. Natl. Acad. Sci. USA 2011, 108, 20690-20694.

43. Junttila, T.T.; Parsons, K.; Olsson, C.; Lu, Y.; Xin, Y.; Theriault, J.; Crocker, L.; Pabonan, O.; Baginski, T.; Meng, G.; et al. Superior In vivo Efficacy of Afucosylated Trastuzumab in the Treatment of HER2-Amplified Breast Cancer. Cancer Res. 2010, 70, 4481-4489.

44. Ferrara, C.; Grau, S.; Jäger, C.; Sondermann, P.; Brünker, P.; Waldhauer, I.; Hennig, M.; Ruf, A.; Rufer, A.C.; Stihle, M.; et al. Unique carbohydrate-carbohydrate interactions are required for high affinity binding between FcgammaRIII and antibodies lacking core fucose. Proc. Natl. Acad. Sci. USA 2011, 108, 12669-12674.

45. Ferrara, C.C.; Stuart, F.F.; Sondermann, P.P.; Brünker, P.P.; Umaña, P.P. The carbohydrate at FcgammaRIIIa Asn-162. An element required for high affinity binding to non-fucosylated IgG glycoforms. J. Biol. Chem. 2006, 281, 5032-5036.

46. Davies, J.; Jiang, L.; Pan, L.Z.; LaBarre, M.J.; Anderson, D.; Reff, M. Expression of GnTIII in a recombinant anti-CD20 $\mathrm{CHO}$ production cell line: Expression of antibodies with altered glycoforms leads to an increase in ADCC through higher affinity for FC gamma RIII. Biotechnol. Bioeng. 2001, 74, 288-294.

47. Umaña, P.; Jean-Mairet, J.; Moudry, R.; Amstutz, H.; Bailey, J.E. Engineered glycoforms of an antineuroblastoma IgG1 with optimized antibody-dependent cellular cytotoxic activity. Nat. Biotechnol. 1999, 17, 176-180.

48. Hodoniczky, J.; Zheng, Y.Z.; James, D.C. Control of recombinant monoclonal antibody effector functions by Fc N-glycan remodeling in vitro. Biotechnol. Prog. 2005, 21, 1644-1652.

49. Boyd, P.N.; Lines, A.C.; Patel, A.K. The effect of the removal of sialic acid, galactose and total carbohydrate on the functional activity of Campath-1H. Mol. Immunol. 1995, 32, 1311-1318.

50. Nimmerjahn, F.; Anthony, R.M.; Ravetch, J.V. Agalactosylated IgG antibodies depend on cellular Fc receptors for in vivo activity. Proc. Natl. Acad. Sci. USA 2007, 104, 8433-8437. 
51. Malhotra, R.; Wormald, M.R.; Rudd, P.M.; Fischer, P.B.; Dwek, R.A.; Sim, R.B. Glycosylation changes of IgG associated with rheumatooid arthritis can activate complement via the mannose-binding protein. Nat. Med. 1995, 1, 237-243.

52. Ackerman, M.E.; Crispin, M.; Yu, X.; Baruah, K.; Boesch, A.W.; Harvey, D.J.; Dugast, A.-S.; Heizen, E.L.; Ercan, A.; Choi, I.; et al. Natural variation in Fc glycosylation of HIV-specific antibodies impacts antiviral activity. J. Clin. Invest. 2013, 123, 2183-2192.

53. Karsten, C.M.C.; Pandey, M.K.M.; Figge, J.J.; Kilchenstein, R.R.; Taylor, P.R.P.; Rosas, M.M.; McDonald, J.U.J.; Orr, S.J.S.; Berger, M.M.; Petzold, D.D.; et al. Anti-inflammatory activity of IgG1 mediated by Fc galactosylation and association of FcyRIIB and dectin-1. Nat. Med. 2012, 18, 1401-1406.

54. Kaneko, Y.; Nimmerjahn, F.; Ravetch, J.V. Anti-inflammatory activity of immunoglobulin G resulting from Fc sialylation. Science 2006, 313, 670-673.

55. Anthony, R.M.; Nimmerjahn, F.; Ashline, D.J.; Reinhold, V.N.; Paulson, J.C.; Ravetch, J.V. Recapitulation of IVIG Anti-Inflammatory Activity with a Recombinant IgG Fc. Science 2008, 320, 373-376.

56. Anthony, R.M.; Kobayashi, T.; Wermeling, F.; Ravetch, J.V. Intravenous gammaglobulin suppresses inflammation through a novel $\mathrm{T}(\mathrm{H}) 2$ pathway. Nature 2011, 475, 110-113.

57. Anthony, R.M.R.; Wermeling, F.F.; Karlsson, M.C.I.M.; Ravetch, J.V.J. Identification of a receptor required for the anti-inflammatory activity of IVIG. Proc. Natl. Acad. Sci. USA 2008, 105, 19571-19578.

58. Schwab, I.; Biburger, M.; Krönke, G.; Schett, G.; Nimmerjahn, F. IVIg-mediated amelioration of ITP in mice is dependent on sialic acid and SIGNR1. Eur. J. Immunol. 2012, 42, 826-830.

59. Scallon, B.J.; Tam, S.H.; McCarthy, S.G.; Cai, A.N.; Raju, T.S. Higher levels of sialylated Fc glycans in immunoglobulin $\mathrm{G}$ molecules can adversely impact functionality. Mol. Immunol. 2007, 44, 1524-1534.

60. Imbach, P.; Wagner, H.P.; Berchtold, W.; Gaedicke, G.; Hirt, A.; Joller, P.; Mueller-Eckhardt, C.; Müller, B.; Rossi, E.; Barandun, S. Intravenous immunoglobulin versus oral corticosteroids in acute immune thrombocytopenic purpura in childhood. Lancet 1985, 2, 464-468.

61. Levy, Y.; Sherer, Y.; Ahmed, A.; Langevitz, P.; George, J.; Fabbrizzi, F.; Terryberry, J.; Meissner, M.; Lorber, M.; Peter, J.B.; et al. A study of 20 SLE patients with intravenous immunoglobulin-Clinical and serologic response. Lupus 1999, 8, 705-712.

62. Hughes, R.A.C.R.; Donofrio, P.P.; Bril, V.V.; Dalakas, M.C.M.; Deng, C.C.; Hanna, K.K.; Hartung, H.-P.H.; Latov, N.; Merkies, I.S.J.I.; van Doorn, P.A.P. Intravenous immune globulin $(10 \%$ caprylate-chromatography purified) for the treatment of chronic inflammatory demyelinating polyradiculoneuropathy (ICE study): A randomised placebo-controlled trial. Lancet Neurol. 2008, 7, 136-144.

63. Kaneko, Y.Y.; Nimmerjahn, F.F.; Madaio, M.P.M.; Ravetch, J.V.J. Pathology and protection in nephrotoxic nephritis is determined by selective engagement of specific Fc receptors. J. Exp. Med. 2006, 203, 789-797. 
64. Guhr, T.T.; Bloem, J.J.; Derksen, N.I.L.N.; Wuhrer, M.M.; Koenderman, A.H.L.A.; Aalberse, R.C.R.; Rispens, T.T. Enrichment of sialylated IgG by lectin fractionation does not enhance the efficacy of immunoglobulin $\mathrm{G}$ in a murine model of immune thrombocytopenia. PLoS One 2011, 6, e21246.

65. Leontyev, D.; Katsman, Y.; Ma, X.-Z.; Miescher, S.; Käsermann, F.; Branch, D.R. Sialylation-independent mechanism involved in the amelioration of murine immune thrombocytopenia using intravenous gammaglobulin. Transfusion 2012, 52, 1799-1805.

66. Sondermann, P.; Pincetic, A.; Maamary, J.; Lammens, K.; Ravetch, J.V. General mechanism for modulating immunoglobulin effector function. Proc. Natl. Acad. Sci. USA 2013, 110, 9868-9873.

67. Richards, M.L.M.; Katz, D.H.D. The binding of $\operatorname{IgE}$ to murine Fc epsilon RII is calcium-dependent but not inhibited by carbohydrate. J. Immunol. 1990,144, 2638-2646.

68. Yu, X.; Vasiljevic, S.; Mitchell, D.A.; Crispin, M.; Scanlan, C.N. Dissecting the Molecular Mechanism of IVIg Therapy: The Interaction between Serum IgG and DC-SIGN is Independent of Antibody Glycoform or Fc Domain. J. Mol. Biol. 2013, 425, 1253-1258.

69. Oaks, M.; Taylor, S.; Shaffer, J. Autoantibodies targeting tumor-associated antigens in metastatic cancer: Sialylated IgGs as candidate anti-inflammatory antibodies. OncoImmunology 2013, 2, eLocation ID: e24841.

70. Käsermann, F.F.; Boerema, D.J.D.; Rüegsegger, M.M.; Hofmann, A.A.; Wymann, S.S.; Zuercher, A.W.A.; Miescher, S.S. Analysis and functional consequences of increased Fab-sialylation of intravenous immunoglobulin (IVIG) after lectin fractionation. PLoS One 2012, 7, e37243.

71. Barb, A.W.A.; Prestegard, J.H.J. NMR analysis demonstrates immunoglobulin G N-glycans are accessible and dynamic. Nat. Chem. Biol. 2011, 7, 147-153.

72. Gerdes, C.A.; Nicolini, V.; Herter, S.; van Puijenbroek, E.; Lang, S.; Roemmele, M.; Moessner, E.; Freytag, O.; Friess, T.; Ries, C.H.; et al. GA201 (RG7160): A novel, humanised, glycoengineered anti-EGFR antibody with enhanced ADCC and superior in vivo efficacy compared with cetuximab. Clin. Cancer Res. 2012, 19, 1126.

73. Gasdaska, J.R.; Sherwood, S.; Regan, J.T.; Dickey, L.F. An afucosylated anti-CD20 monoclonal antibody with greater antibody-dependent cellular cytotoxicity and B-cell depletion and lower complement-dependent cytotoxicity than rituximab. Mol. Immunol. 2012, 50, 134-141.

74. van de Geijn, F.E.; Wuhrer, M.; Selman, M.H.J.; Willemsen, S.P.; de Man, Y.A.; Deelder, A.M.; Hazes, J.M.W.; Dolhain, R.J. Immunoglobulin G galactosylation and sialylation are associated with pregnancy-induced improvement of rheumatoid arthritis and the postpartum flare: Results from a large prospective cohort study. Arthritis Res. Ther. 2009, 11, R193-R193.

75. Rook, G.A.W.; Steele, J.; Brealey, R.; Whyte, A.; Isenberg, D.; Sumar, N.; Nelson, J.L.; Bodman, K.B.; Young, A.; Roitt, I.M.; et al. Changes in IgG glycoform levels are associated with remission of arthritis during pregnancy. Trends Biotechnol. 1991, 4, 779-794.

76. Parekh, R.R.; Roitt, I.I.; Isenberg, D.D.; Dwek, R.R.; Rademacher, T.T. Age-related galactosylation of the N-linked oligosaccharides of human serum IgG. J. Exp. Med. 1988, 167, $1731-1736$. 
77. Shikata, K.K.; Yasuda, T.T.; Takeuchi, F.; Konishi, T.T.; Nakata, M.M.; Mizuochi, T.T. Structural changes in the oligosaccharide moiety of human IgG with aging. Glycoconjug. J. 1998, 15, 683-689.

78. Parekh, R.B.; Dwek, R.A.; Sutton, B.J.; Fernandes, D.L.; Leung, A.; Stanworth, D.; Rademacher, T.W. Association of rheumatoid arthritis and primary osteoarthritis with changes in the glycosylation pattern of total serum IgG. Nature 1985, 316, 452-457.

79. Parekh, R.B.; Roitt, I.M.; Isenberg, D.A.; Dwek, R.A.; Ansell, B.M.; Rademacher, T.W. Galactosylation of IgG associated oligosaccharides: Reduction in patients with adult and juvenile onset rheumatoid arthritis and relation to disease activity. Lancet 1988, 1, 966-969.

80. Espy, C.C.; Morelle, W.W.; Kavian, N.N.; Grange, P.P.; Goulvestre, C.C.; Viallon, V.V.; Chéreau, C.C.; Pagnoux, C.C.; Michalski, J.-C.J.; Guillevin, L.L.; et al. Sialylation levels of anti-proteinase 3 antibodies are associated with the activity of granulomatosis with polyangiitis (Wegener's). Arthritis Rheum. 2011, 63, 2105-2115.

81. Parekh, R.; Isenberg, D.; Rook, G.; Roitt, I.; Dwek, R.; Rademacher, T. A comparative analysis of disease-associated changes in the galactosylation of serum IgG. Trends Biotechnol. 1989, 2, 101-114.

82. Mehta, A.S.; Long, R.E.; Comunale, M.A.; Wang, M.; Rodemich, L.; Krakover, J.; Philip, R.; Marrero, J.A.; Dwek, R.A.; Block, T.M. Increased levels of galactose-deficient anti-Gal immunoglobulin $\mathrm{G}$ in the sera of hepatitis $\mathrm{C}$ virus-infected individuals with fibrosis and cirrhosis. J. Virol. 2008, 82, 1259-1270.

83. Kodar, K.K.; Stadlmann, J.J.; Klaamas, K.K.; Sergeyev, B.B.; Kurtenkov, O.O. Immunoglobulin $\mathrm{G}$ Fc N-glycan profiling in patients with gastric cancer by LC-ESI-MS: Relation to tumor progression and survival. Glycoconjug. J. 2012, 29, 57-66.

84. Saldova, R.R.; Royle, L.L.; Radcliffe, C.M.C.; Hamid, U.M.U.A.; Evans, R.R.; Arnold, J.N.J.; Banks, R.E.R.; Hutson, R.R.; Harvey, D.J.D.; Antrobus, R.R.; et al. Ovarian cancer is associated with changes in glycosylation in both acute-phase proteins and IgG. Glycobiology 2007, 17, 1344-1356.

85. Scherer, H.U.H.; van der Woude, D.D.; Ioan-Facsinay, A.A.; Bannoudi, el, H.H.; Trouw, L.A. L.; Wang, J.J.; Häupl, T.T.; Burmester, G.-R.G.; Deelder, A.M.A.; Huizinga, T.W.J.T.; et al. Glycan profiling of anti-citrullinated protein antibodies isolated from human serum and synovial fluid. Arthritis Rheum. 2010, 62, 1620-1629.

86. Pekelharing, J.M.; Hepp, E.; Kamerling, J.P.; Gerwig, G.J.; Leijnse, B. Alterations in carbohydrate composition of serum IgG from patients with rheumatoid arthritis and from pregnant women. Ann. Rheum. Dis. 1988, 47, 91-95.

87. Gornik, I.I.; Maravić, G.G.; Dumić, J.J.; Flögel, M.M.; Lauc, G.G. Fucosylation of IgG heavy chains is increased in rheumatoid arthritis. Clin. Biochem. 1999, 32, 605-608.

88. Guo, N.; Liu, Y.; Masuda, Y.; Kawagoe, M.; Ueno, Y.; Kameda, T.; Sugiyama, T. Repeated immunization induces the increase in fucose content on antigen-specific IgG N-linked oligosaccharides. Clin. Biochem. 2005, 38, 149-153.

89. Wang, J.; Balog, C.I.A.; Stavenhagen, K.; Koeleman, C.A.M.; Scherer, H.U.; Selman, M.H.J.; Deelder, A.M.; Huizinga, T.W.J.; Toes, R.E.M.; Wuhrer, M. Fc-glycosylation of IgG1 is modulated by B-cell stimuli. Mol. Cell. Proteomics 2011, 10, M110.004655. 
90. Croce, A.; Firuzi, O.; Altieri, F.; Eufemi, M.; Agostino, R.; Priori, R.; Bombardieri, M.; Alessandri, C.; Valesini, G.; Saso, L. Effect of infliximab on the glycosylation of IgG of patients with rheumatoid arthritis. J. Clin. Lab. Anal. 2007, 21, 303-314.

91. Pasek, M.; Duk, M.; Podbielska, M.; Sokolik, R.; Szechiński, J.; Lisowska, E.; Krotkiewski, H. Galactosylation of IgG from rheumatoid arthritis (RA) patients-Changes during therapy. Glycoconjug. J. 2006, 23, 463-471.

92. Axford, J.S.J. Decreased B-cell galactosyltransferase activity in rheumatoid arthritis. Rheumatology (Oxford) 1988, 27, 170.

93. Furukawa, K.K.; Matsuta, K.K.; Takeuchi, F.F.; Kosuge, E.E.; Miyamoto, T.T.; Kobata, A.A. Kinetic study of a galactosyltransferase in the B cells of patients with rheumatoid arthritis. Int. Immunol. 1990, 2, 105-112.

94. Axford, J.S.; Sumar, N.; Alavi, A.; Isenberg, D.A.; Young, A.; Bodman, K.B.; Roitt, I.M. Changes in normal glycosylation mechanisms in autoimmune rheumatic disease. J. Clin. Invest. 1992, 89, 1021-1031.

95. Alavi, A.; Axford, J.S.; Pool, A.J. Serum galactosyltransferase isoform changes in rheumatoid arthritis. J. Rheumatol. 2004, 31, 1513-1520.

96. Keusch, J.J.; Lydyard, P.M.P.; Berger, E.G.E.; Delves, P.J.P. B lymphocyte galactosyltransferase protein levels in normal individuals and in patients with rheumatoid arthritis. Glycoconjug. J. 1998, 15, 1093-1097.

97. Jeddi, P.A.P.; Bodman-Smith, K.B.K.; Lund, T.T.; Lydyard, P.M.P.; Mengle-Gaw, L.L.; Isenberg, D.A.D.; Youinou, P.P.; Delves, P.J.P. Agalactosyl IgG and beta-1,4-galactosyltransferase gene expression in rheumatoid arthritis patients and in the arthritis-prone MRL lpr/lpr mouse. Immunology 1996, 87, 654-659.

98. Omtvedt, L.A.; Royle, L.; Husby, G.; Sletten, K.; Radcliffe, C.M.; Harvey, D.J.; Dwek, R.A.; Rudd, P.M. Glycan analysis of monoclonal antibodies secreted in deposition disorders indicates that subsets of plasma cells differentially process IgG glycans. Arthritis Rheum. 2006, 54, 3433-3440.

99. Nasirikenari, M.; Chandrasekaran, E.V.; Matta, K.L.; Segal, B.H.; Bogner, P.N.; Lugade, A.A.; Thanavala, Y.; Lee, J.J.; Lau, J.T.Y. Altered eosinophil profile in mice with ST6Gal-1 deficiency: an additional role for ST6Gal-1 generated by the P1 promoter in regulating allergic inflammation. J. Leukoc. Biol. 2010, 87, 457-466.

100. Jones, M.B.; Nasirikenari, M.; Lugade, A.A.; Thanavala, Y.; Lau, J.T.Y. Anti-inflammatory IgG Production Requires Functional P1 Promoter in -Galactoside 2,6-Sialyltransferase 1 (ST6Gal-1) Gene. J. Biol. Chem. 2012, 287, 15365-15370.

101. Gould, H.J.; Sutton, B.J. IgE in allergy and asthma today. Nat. Rev. Immunol. 2008, 8, 205-217.

102. Galli, S.J.; Tsai, M. IgE and mast cells in allergic disease. Nat. Med. 2012, 18, 693-704.

103. Dorrington, K.J.; Bennich, H.H. Structure-function relationships in human immunoglobulin E. Immunol. Rev. 1978, 41, 3-25.

104. Arnold, J.N.J.; Radcliffe, C.M.C.; Wormald, M.R.M.; Royle, L.L.; Harvey, D.J.D.; Crispin, M.M.; Dwek, R.A.R.; Sim, R.B.R.; Rudd, P.M.P. The glycosylation of human serum IgD and IgE and the accessibility of identified oligomannose structures for interaction with mannan-binding lectin. J. Immunol. 2004, 173, 6831-6840. 
105. Basu, M.M.; Hakimi, J.J.; Dharm, E.E.; Kondas, J.A.J.; Tsien, W.H.W.; Pilson, R.S.R.; Lin, P.P.; Gilfillan, A.A.; Haring, P.P.; Braswell, E.H.E. Purification and characterization of human recombinant IgE-Fc fragments that bind to the human high affinity IgE receptor. J. Biol. Chem. 1993, 268, 13118-13127.

106. Young, R.J.R.; Owens, R.J.R.; Mackay, G.A.G.; Chan, C.M.C.; Shi, J.J.; Hide, M.M.; Francis, D.M.D.; Henry, A.J.A.; Sutton, B.J.B.; Gould, H.J.H. Secretion of recombinant human IgE-Fc by mammalian cells and biological activity of glycosylation site mutants. Protein Eng. 1995, 8, 193-199.

107. Björklund, J.E.M.; Karlsson, T.; Magnusson, C.G.M. N-glycosylation influences epitope expression and receptor binding structures in human IgE. Mol. Immunol. 1999, 36, 213-221.

108. Björklund, J.E.; Schmidt, M.; Magnusson, C.G. Characterisation of recombinant human IgE-Fc fragments expressed in baculovirus-infected insect cells. Mol. Immunol. 2000, 37, 169-177.

109. Garman, S.C.; Wurzburg, B.A.; Tarchevskaya, S.S.; Kinet, J.P.; Jardetzky, T.S. Structure of the Fc fragment of human IgE bound to its high-affinity receptor Fc epsilonRI alpha. Nature 2000, 406, 259-266.

110. Nettleton, M.Y.; Kochan, J.P. Role of Glycosylation Sites in the IgE Fc Molecule. Int. Arch. Allergy Immunol. 1995, 107, 328-329.

111. Vercelli, D.; Helm, B.; Marsh, P.; Padlan, E.; Geha, R.S.; Gouid, H. The B-cell binding site on human immunoglobulin E. Nature 1989, 338, 649-651.

112. Nadesalingam, J.J.; Reid, K.B.M.K.; Palaniyar, N.N. Collectin surfactant protein D binds antibodies and interlinks innate and adaptive immune systems. FEBS Lett. 2005, 579, 4449-4453.

113. Rutishauser, U.; Acheson, A.; Hall, A.K.; Mann, D.M.; Sunshine, J. The neural cell adhesion molecule (NCAM) as a regulator of cell-cell interactions. Science 1988, 240, 53-57.

114. Monteiro, R.C. The role of $\operatorname{IgA}$ and $\operatorname{IgA}$ Fc receptors as anti-inflammatory agents. J. Clin. Immunol. 2010, 30, S61-S64.

115. Bakema, J.E.J.; van Egmond, M.M. Immunoglobulin A: A next generation of therapeutic antibodies? J. Biol. Chem. 2011, 3, 352-361.

116. Novak, J.J.; Julian, B.A.B.; Mestecky, J.J.; Renfrow, M.B.M. Glycosylation of IgA1 and pathogenesis of IgA nephropathy. Semin. Immunopathol. 2012, 34, 365-382.

117. Mattu, T.S.; Pleass, R.J.; Willis, A.C.; Kilian, M.; Wormald, M.R.; Lellouch, A.C.; Rudd, P.M.; Woof, J.M.; Dwek, R.A. The glycosylation and structure of human serum IgA1, Fab, and Fc regions and the role of $\mathrm{N}$-glycosylation on Fc alpha receptor interactions. J. Biol. Chem. 1998, 273, 2260-2272.

118. Carayannopoulos, L.; Max, E.E.; Capra, J.D. Recombinant human IgA expressed in insect cells. Proc. Natl. Acad. Sci. USA 1994, 91, 8348-8352.

119. Basset, C.C.; Durand, V.V.; Jamin, C.C.; Clément, J.J.; Pennec, Y.Y.; Youinou, P.P.; Dueymes, M.M.; Roitt, I.M.I. Increased N-linked glycosylation leading to oversialylation of monomeric immunoglobulin A1 from patients with Sjögren's syndrome. Scand. J. Immunol. 2000, 51, 300-306.

120. Suzuki, H.; Moldoveanu, Z.; Hall, S.; Brown, R.; Vu, H.L.; Novak, L.; Julian, B.A.; Tomana, M.; Wyatt, R.J.; Edberg, J.C.; et al. IgA1-secreting cell lines from patients with IgA nephropathy produce aberrantly glycosylated IgA1. J. Clin. Invest. 2008, 118, 629-639. 
121. Tomana, M.; Novak, J.; Julian, B.A.; Matousovic, K.; Konecny, K.; Mestecky, J. Circulating immune complexes in IgA nephropathy consist of IgA1 with galactose-deficient hinge region and antiglycan antibodies. J. Clin. Invest. 1999, 104, 73-81.

122. Coppo, R.; Basolo, B.; Martina, G.; Rollino, C.; De Marchi, M.; Giacchino, F.; Mazzucco, G.; Messina, M.; Piccoli, G. Circulating immune complexes containing IgA, IgG and IgM in patients with primary IgA nephropathy and with Henoch-Schoenlein nephritis. Correlation with clinical and histologic signs of activity. Clin. Nephrol. 1982, 18, 230-239.

123. Lai, K.N. Pathogenesis of IgA nephropathy. Nat. Rev. Nephrol. 2012, 8, 275-283.

124. Arnold, J.N.; Wormald, M.R.; Suter, D.M.; Radcliffe, C.M.; Harvey, D.J.; Dwek, R.A.; Rudd, P.M.; Sim, R.B. Human serum IgM glycosylation: identification of glycoforms that can bind to mannan-binding lectin. J. Biol. Chem. 2005, 280, 29080-29087.

(C) 2013 by the authors; licensee MDPI, Basel, Switzerland. This article is an open access article distributed under the terms and conditions of the Creative Commons Attribution license (http://creativecommons.org/licenses/by/3.0/). 